\title{
Allonursing and Cooperative Birthing Behavior in Yellowstone Bison, Bison bison
}

\author{
JENNIFER D. JONES ${ }^{1}$ and JOHN J. TREANOR ${ }^{2}$
}

National Park Service, Yellowstone National Park, P.O. Box 168, Mammoth, Wyoming 82190 USA; e-mail: Jenny_Jones@ nps.gov.

${ }^{1}$ Present address: University of Wyoming; e-mail: jjones60@uwyo.edu

2e-mail: John Treanor@nps.gov

Jones, Jennifer D., and John J. Treanor. 2008. Allonursing and cooperative birthing behavior in Yellowstone Bison, Bison bison. Canadian Field-Naturalist 122(2): 171-172.

We document allonursing and cooperative birthing behavior in wild Bison near Yellowstone National Park in the western United States. During spring 2007, two female Bison nursed each other's newborn calves and mutually cleaned both calves and consumed expelled birth material. Intensive cooperative birthing behavior has never been documented in wild Bison before. This observation of allonursing might be explained by kin selection and reciprocal altruism.

Key Words: Bison, Bison bison, alloparental care, allonursing, Yellowstone National Park, Montana.

Alloparental care, the investment of resources toward the survival of another's offspring (Hamilton 1964) is expected to negatively affect future reproductive success and the survival of current offspring through physiological stress (Heinsohn and Legge 1999; Roulin 2001). However, this apparently altruistic behavior has been documented in 120 mammalian and 150 avian species (Riedman 1982). In mammals, the nursing of non-genetic offspring, allonursing, is a form of alloparental care that has been observed in 68 mammalian species (Packer et al. 1992; Roulin 2001). The costs and benefits of this energetically expensive behavior are unclear, especially in mammals living in temperate environments where food resources sustaining lactation are limited seasonally.

We observed a unique birthing event and allonursing in Bison (Bison bison) on 27 April 2007 along the shoreline of Hebgen Lake $\left(44^{\circ} 45^{\prime} \mathrm{N} 111^{\circ} 13^{\prime} \mathrm{W}\right)$ near West Yellowstone, Montana. Two female Bison, aged 4-7 years, gave birth within an hour of each other at the same location and shared in the care of each other's calves. Following each birth, both females simultaneously licked the newborn calf and consumed the expelled birth material. Both females also consumed the retained placental tissue protruding from the other birthing female. Each calf was seen nursing from both

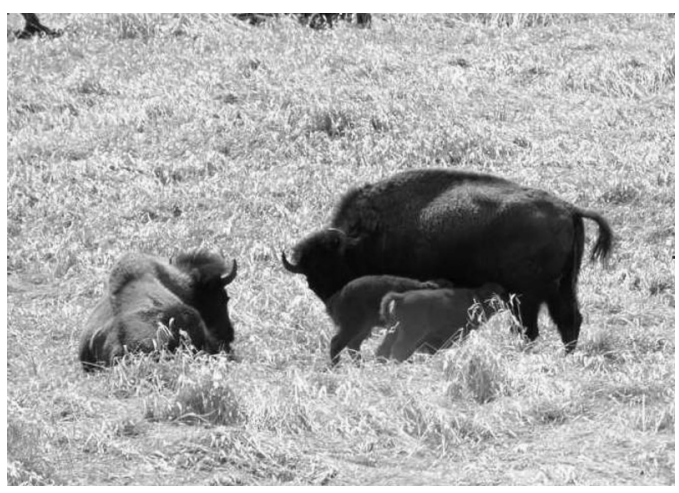

FIGURE 1. Two newborn Bison calves simultaneously nursing from one female during a cooperative birthing event near Yellowstone National Park, Montana, on 27 April 2007. National Parks Service. Photo by Carrie Byron.

females shortly after parturition (Figure 1). We monitored the females and newborns for 5.5 hours, during which the females demonstrated aggressive behavior toward other Bison approaching the birth sites. This is the first documented observation exhibiting intensive cooperative birthing behavior in wild Bison. 
The benefits of allonursing in Bison should outweigh the costs; otherwise a female should not sacrifice her resources at the expense of her own calf's survival. This behavior has been explained through kin selection (Hamilton 1964), reciprocity or sharing the burden with another female (Roulin 2001; CluttonBrock 2002), and limited parenting experience (Riedman 1982). Female Bison imprint on the first calf they contact after giving birth and, while this is usually their calf, it is possible in a herd to mistakenly adopt another female's calf through lack of parenting experience (Lott 1972). Since the females in the observation were estimated to be of prime reproductive age, it is unlikely that this was their first pregnancy and does not lend support for lack of experience as an explanation. We do not know the level of genetic relatedness of the birthing females and therefore can not endorse a strong kin selection explanation for the observed behavior.

Both kin selection and reciprocity may explain our observation of allonursing and cooperative birthing behavior. The sharing of birthing responsibilities between two females benefits both of them, even if they are genetically unrelated. Shared nursing responsibilities could be beneficial to both females if the mammary glands of one female become depleted temporarily. The behavior also provides temporary relief from maternal duties, or each calf receives a greater variety of immune compounds by nursing from multiple females (Roulin 2001). Additionally, Bison calves are targeted by Grizzly Bears (Ursus arctos) and Wolves (Canis lupus) in Yellowstone National Park. Reciprocal behavior extending beyond allonursing to protection from predators may increase the survival probability of newborn Bison. Though Bison are highly social and display cooperative behavior with offspring of other herd members, previously reported cases of alloparental care in Bison are limited. McHugh (1958) did report four instances where Yellowstone Bison calves, ranging from 30 minutes to 20 days old, began to nurse on a cow other than their mother but no details about the cow's reaction is given and it is unclear if the calves were immediately rejected or allowed to nurse. To our knowledge, this is the first documented case of allonursing and extensive cooperative birthing behavior in wild Bison.

\section{Acknowledgments}

We appreciate the hard work put forth by the staff and volunteers of the Bison Ecology and Management Office at the Yellowstone Center for Resources, especially Carrie Byron, Mary Kay Woodin, Doug Blanton, Jeremiah Smith and Chris Geremia. We thank Rick Wallen and P. J. White for helpful reviews of this note.

\section{Literature Cited}

Clutton-Brock, T. 2002. Breeding together: kin selection and mutualism in cooperative vertebrates. Science 296: 69-72.

Hamilton, W. D. 1964. The genetical evolution of social behavior. Journal of Theoretical Biology 7: 1-52.

Heinsohn, R., and S. Legge. 1999. The cost of helping. Trends in Ecology and Evolution 14: 53-57.

Lott, D. F. 1972. The way of the bison: fighting to dominate. Pages 321-333 in The marvels of animal behavior. Edited by J. C. McLoughlin. National Geographic Society, Washington D.C. 422 pages.

McHugh, T. 1958. Social behavior of the American buffalo (Bison bison bison). Zoologica 43(1): 1-40.

Packer, C., S. Lewis, and A. Pusey. 1992. A comparative analysis of non-offspring nursing. Animal Behavior 43: 265-281.

Riedman, M. L. 1982. The evolution of alloparental care and adoption in mammals and birds. Quarterly Review of Biology 57: 405-435.

Roulin, A. 2001. Why do lactating females nurse alien offspring? A review of hypotheses and empirical evidence. Animal Behavior 63: 201-208.

Received 15 July 2008

Accepted 17 February 2009 